\title{
Superabsorbent polymer for water management in forestry
}

\author{
Miguel Casquilho ${ }^{1^{*}}$, Abel Rodrigues ${ }^{2}$, Fátima Rosa ${ }^{1}$ \\ ${ }^{1}$ Department of Chemical Engineering, Center for Chemical Processes, Instituto Superior Técnico, Technical University of Lisbon, \\ Lisbon, Portugal; ${ }^{*}$ Corresponding Author: mcasquilho@ist.utl.pt \\ ${ }^{2}$ Unidade de Produtos Florestais (Forest Products Unit), INIAV, Ministry of Agriculture, Oeiras, Portugal
}

Received 2013

\begin{abstract}
The effectiveness of a super absorbent polymer of sodium polyacrylate was studied, with emphasis on water management, i.e., absorption, retention and desorption in the soil. The polymer was applied in plots with a sandy soil near Grândola (southern Portugal). Characterization of the most relevant physical and chemical properties of the polymer was made, namely, its specific gravity, particle diameter, capacity of water absorption and desorption. In the plots with and without the polymer, soil moisture was continuously monitored, and grassland biomass samples were collected and weighed. The results reflected the effective role of the polymer both in the improvement of the water regime in the soil and in the substantial increment of grassland productivity.
\end{abstract}

Keywords: Absorption; Desorption; Sodium Polyacrylate; Superabsorbent Polymer; SAP

\section{INTRODUCTION}

A superabsorbent polymer (SAP) is a hydrogel that absorbs water hundreds of times its own dry mass. Usually a SAP is produced by the polymerization of acrylic acid, acrylic esters, acrylamide and other unsaturated monomers. The carboxylic group along the polymer chain facilitates the absorption of water, while the presence of crosslinking in the chain prevents their complete solubilization $([1,4])$. The superabsorbent materials are of great interest due to their applications, namely in medicine and in solving some ecological and biological problems, in biomedicine, biotechnology, pharmaceutical, veterinary, food industry, and, addressed in this study, agriculture technologies. Specifically, they are used as controlled release systems of drugs, pesticides, water or other bioactive agents.

Great attention has been given to the application of superabsorbent hydrogels in agriculture, soil improvement and plant growth. Superabsorbent hydrogel particles distributed in the soil are capable of absorbing water. This should efficiently improve the management of water, through the water-holding capacity of the soil, and promote optimal plant growth $([3,4])$. One of the polymers that showed greatest results in this area was sodium polyacrylate, used in this study, and applied in 4 plots in the Grândola region, southern Portugal, a Mediterranean area with hot summers, leading to water stress, corresponding to the kind of environment where the effects of SAPs should be more useful as attenuators of summer water scarcity to plants.

\section{MATERIALS AND METHODS}

The SAP's specific gravity was determined using a calibrated pycnometer containing a sample of the SAP in a non-solvent test liquid, $n$-heptane, with a total known volume. The dry sample was weighed and placed in the pycnometer, which then was filled with the test liquid and weighed. The specific gravity was calculated as the quotient of the dry mass to this volume.

A SAP's capacity to absorb water is considered the maximum mass that it can absorb when submerged in water, leading to its "swelling". Swelling experiments were conducted to observe the swelling kinetics of the polymer tested. The water uptake in sodium polyacrylate was measured in the laboratory by the "tea-bag" method. Each bag, with polymer particles, was placed in approximately $200 \mathrm{~mL}$ of water, and the weight of the loaded bag was periodically measured until no weight change was observed. The water uptake ratio, $Q$, was determined as the water absorption amount divided by the initial polymer weight, as in Eq.1, where $W_{0}$ and $W_{t}$ are the weights of samples with water in the bag at the initial time, 0 , and at successive instants of time, $t$, respectively.

$$
Q=\frac{W_{t}-W_{0}}{W_{0}}
$$


The water desorption kinetics from SAP particles was also measured. After samples of the polymer in water reached their equilibrium (maximum) swelling, they were dispersed in samples of soil collected from the plots where the polymer was applied. These samples were periodically weighed till equilibrium. Desorption time for soil without polymer particles was also measured. The water desorption ratio ( $Q$ ') was determined as the water desorption amount divided by the initial sample weight, analogously given in Eq.2,

$$
Q^{\prime}=\frac{W_{t}^{\prime}-W_{0}^{\prime}}{W_{0}^{\prime}}
$$

where $W^{\prime}{ }_{0}$ and $W^{\prime}{ }_{t}$ are weights of the samples at initial time and $t$, respectively. In these absorption and desorption experiments, the same measurements were repeated three times for each sample. The water absorption and desorption ratios and rates were the averaged results of the lab trials.

\section{RESULTS AND DISCUSSION}

The average specific gravity of the polymer particles, determined by the method mentioned was $1.5 \mathrm{~g} \cdot \mathrm{cm}^{-3}$, and the resulting particle diameter was about $438 \mu \mathrm{m}$. Absorption capacity in $\mathrm{mL}$ of distilled water per gram of dry polymer is shown in Figure $\mathbf{1}$ for various diameters tested. The absorption capacity varies from about 270 to $360 \mathrm{~mL}$ per gram of dry polymer, for particle sizes between 63 and $710 \mu \mathrm{m}$.

As shown in Figure 2, the water absorption rate increased with decreasing particle size. Decreases in particle size led to increases in the surface area per unit of polymer mass, resulting in more rapid water adsorption on particle surfaces. The lower the particle size, the faster is the absorption process. For greater particles, the full absorption process takes more time than for a smaller particle. For example, for particles with $63 \mu \mathrm{m}$ it takes about 7 minutes, while for a $425 \mu \mathrm{m}$ particle, it takes about 15 minutes.

Figure 3 shows the water desorption kinetics of polymer particles premixed with soil. The net amount of water initially absorbed in polymer-dispersed soil was practically 2 times higher than that in pure soil. A slightly higher initial water desorption was observed for soils with smaller polymer particles. The time of water evaporation from the soil was significantly affected by the presence of polymer particles. About 25000 min (17 days) were required for SAP-incorporated soils, but only $13000 \mathrm{~min}$ (9 days) for pure soil. The particle-size effect on the water-releasing kinetics from SAP-loaded soils was negligible compared with the water-releasing kinetics from pure soil.

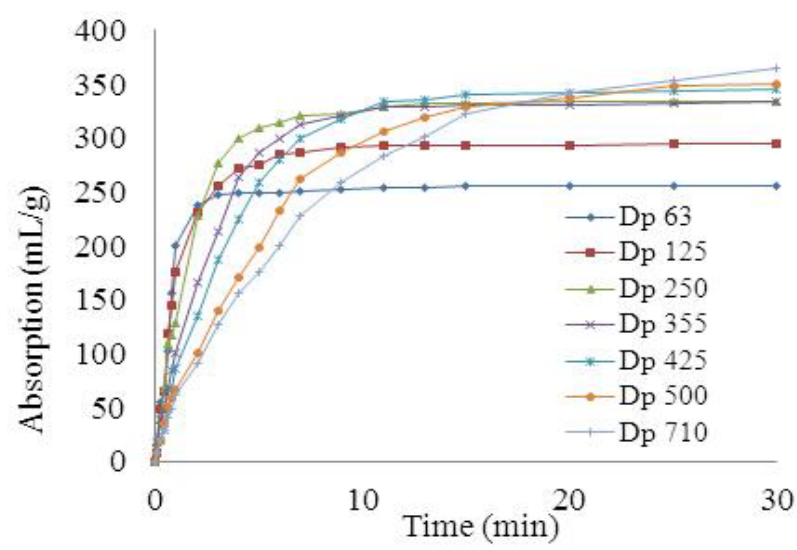

Figure 1. Absorption capacity of SAP particles with different diameters (Dp).

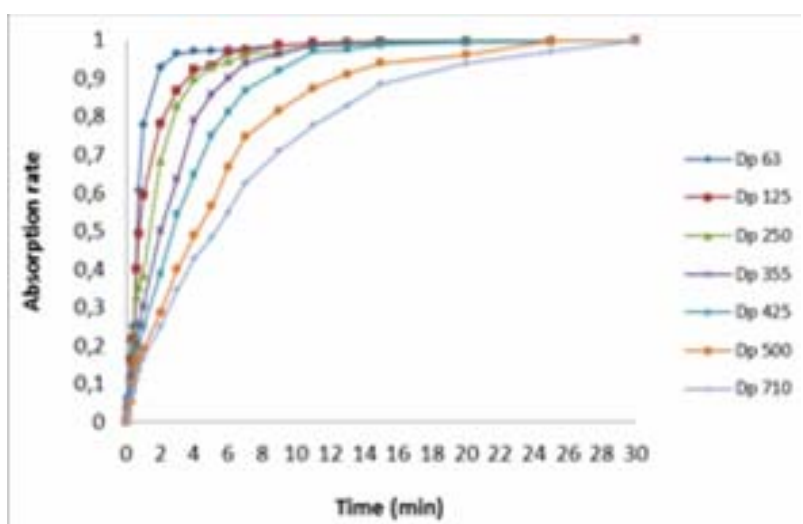

Figure 2. Absorption capacity of SAP particles with different diameters (Dp) as a function of time.

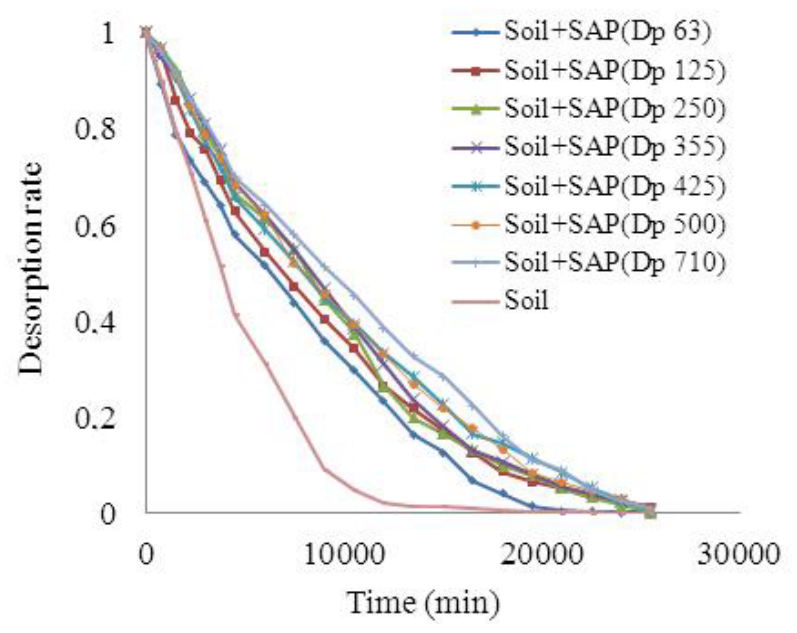

Figure 3. Water desorption kinetics of SAP particles premixed with soil.

\section{Field Work}

The SAP was applied on 4 plots of $2500 \mathrm{~m}^{2}$ each, with a sandy soil and a wavy terrain, according to the experimental design on Figure 3. All the plots were sown with 
a blend of gramineous and leguminous seeds, the latter inoculated with specific Rhizobium. An NPK fertilization was made in all the plots, except the blank, Q4. As shown in Figure 4: plot Q1 received $100 \mathrm{~kg}$ of fertilizer, $4 \mathrm{~kg}$ of SAP, plus $6.25 \mathrm{~kg}$ of seed, as mentioned; plot Q2, same as Q1 but $140 \mathrm{~kg}$ of fertilizer; and plot Q3, same as Q1 but no SAP. To evaluate the effect of SAP biomass productivity, grassland biomass samples were collected and weighed. Three samples per quadrant were taken from several locations, to randomize effects such as soil slope or solar exposition. Specimens were collected from a surface area of $\sim 1 \mathrm{~m}^{2}$, following a square shape. Then, the biomass samples, screened from small branches, and residues were dried in a kiln, at $85^{\circ} \mathrm{C}$ for about 30 hours, till constant weight.

The average results (per $1 \mathrm{~m}^{2}$ ) were: $73 \mathrm{~g}$ for Q1, 100 $\mathrm{g}$ for Q2; and $62 \mathrm{~g}$ for Q3. As can be seen, the plot with greatest biomass production, Q2, is the one containing SAP and an extra dose of fertilizer. The results show increases of 17\% from Q3 to Q1, and 38\% from Q1 to Q2.

It is noted that the application of SAP plus fertilizer alone produced an increase of (17\%) on the growth of vegetation, an increase which presents itself as a very favorable result, taking into account the low levels of precipitation in the region (about $70 \mathrm{~mm}$ ) during the first half of the year of 2012.

In order to obtain data about moisture and soil temperature, as well as precipitation and relative humidity of air, an automatic weather station was installed providing continuous micrometeorological data during Sep-Oct 2012. The effectiveness of the SAP is verified through the soil moisture data in the periods following the occurrence of precipitation, depicted in Figure 5.

Analyzing Figure 5, in the periods following the second and third precipitation zone (the zone between the 5.th and 6.th days and between the 8.th and 9.th, respectively) a trend may be identified (though slight) for an increase in moisture content of the soil in areas where the polymer was applied. Especially after the 2.nd cycle, between the days 16 and 24, an improvement in water retention can be observed. It appears that as time passes since the occurrence of precipitation, the effect of the polymer in the soil moisture content is more notorious.

\begin{tabular}{|c|c|}
\hline \begin{tabular}{|c|} 
Q1 \\
Fertilizer \\
NPK (0-20-17): $100 \mathrm{~kg}$ \\
Blend \\
(fertilizer, limestone) \\
SAP: 4 kg, \\
+ fertilizer and seed \\
\end{tabular} & $\begin{array}{c}\text { Fertilizer } \\
\text { Q2 } \\
\text { NPK (0-20-17): } 140 \mathrm{~kg} \\
\text { Blend } \\
\text { (fertilizer, limestone) } \\
\text { SAP: } 4 \mathrm{~kg}, \\
\text { + fertilizer and seed } \\
\end{array}$ \\
\hline \begin{tabular}{|c|} 
Fertilizer \\
NPK (0-20-17): $100 \mathrm{~kg}$ \\
Grassland: improved \\
Blend \\
(fertilizer, limestone) \\
Q3 $\quad$
\end{tabular} & Blank \\
\hline
\end{tabular}

Figure 4. Experimental design of the polymer application.
As would be expected from the short period during which these data were collected, and given the frequent occurrence of precipitation, the observed effects were barely noticeable, showing an effective retention of water by the applied SAP. The effect of the use of the polymer is illustrated in Figure 6, in which the upper and lower

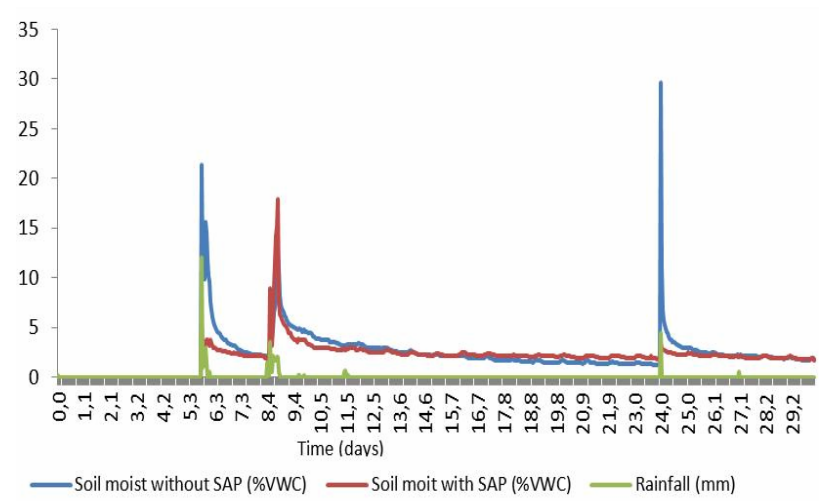

Figure 5. Precipitation (mm) and volumetric moisture (\% v) of the soil.

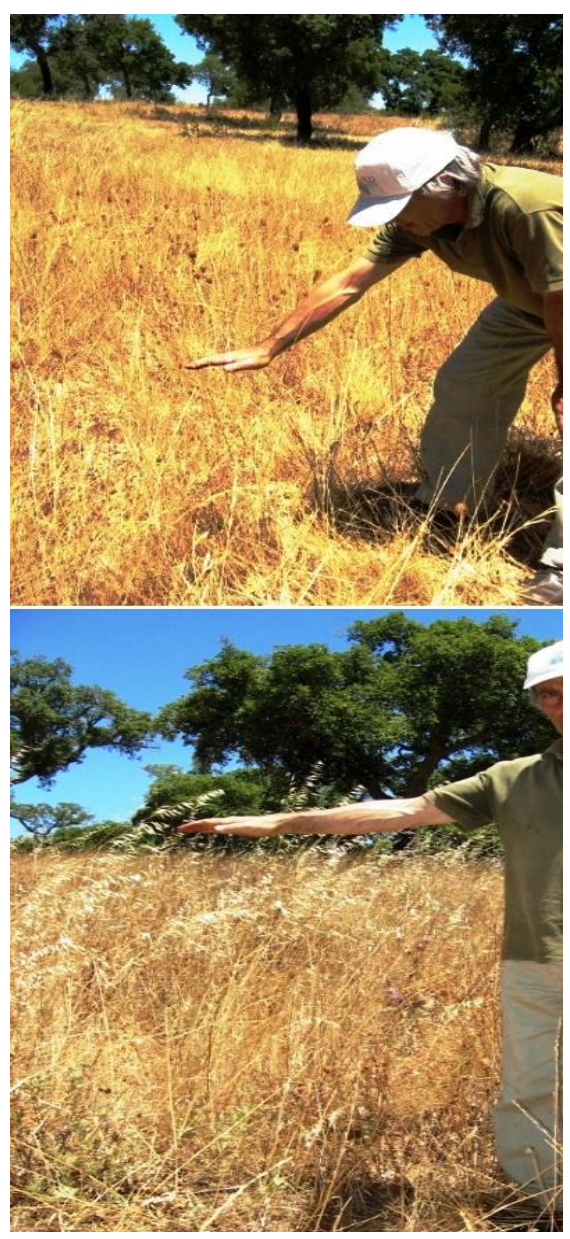

Figure 6. Height of vegetation grown without (upper photo) and with (lower photo) SAP. 
photos show the height of vegetation, respectively, without and with the application of the SAP.

\section{CONCLUSIONS}

A SAP of sodium polyacrilate showed to be an effective agent in increasing biomass productivity in grasslands, improving organic matter content and soil fertility in a study in a region with Mediterranean type climate, i.e., hot summers, in the South of Portugal. The amount of biomass grown in the plots where SAP was applied was significantly greater than in the plots without SAP. The results of soil moisture retention by SAP proved satisfactory, especially in periods after the occurrence of precipitation. These effects, run only in two months, are indicative of success, which should be quantified for a whole hydrological year aiming to test its full potential as soil water stress restrainers in vegetal environments.

\section{ACKNOWLEDGEMENTS}

A SAP of sodium polyacrilate showed to be an effective agent in increasing biomass productivity in grasslands, improving organic matter content and soil fertility in a study in a region with Mediterranean type climate, i.e., hot summers, in the South of Portugal. The amount of biomass grown in the plots where SAP was applied was significantly greater than in the plots without SAP. The results of soil moisture re- tention by SAP proved satisfactory, especially in periods after the occurrence of precipitation. These effects, run only in two months, are indicative of success, which should be quantified for a whole hydrological year aiming to test its full potential as soil water stress restrainers in vegetal environments.

\section{REFERENCES}

[1] Allcock, H.R. and Lampe, F.W. (1990) Contemporary Polymer Chemistry, 2.nd ed., Prentice-Hall, Inc., Englewood Cliffs, New Jersey, USA. ISBN: 0131705490.

[2] Buchholz, F.L. and Graham, A.T. (1998) Modern superabsorbent polymer technology, Wiley-VCH, New York, NY (USA). ISBN: 0-471-19411-5.

[3] $M^{2}$ Polymer Technologies, Inc. (2009) History of super absorbent polymer chemistry, accessed July, 2012. http://www.m2polymer.com/html/history_of_superabsorb ents.html.

[4] Hüttermann, A., Zommorodi, M. and Reise, K. (1999) Addition of hydrogels to soil for prolonging the survival of Pinus halepensis seedling subjected to drought. Soil and Tillage Research, 50, 295-304. doi:10.1016/S0167-1987(99)00023-9

[5] Kos, B. and Leštan, D. (2003) Induced phytoextraction/soil washing of Lead using biodegradable chelate and permeable barriers, Environ. Science \& Technology, 37, 624-629. doi:10.1021/es0200793 